\title{
Memória: 80 anos do Serviço Social no Brasil: 0 III CBAS "0 Congresso da Virada" 1979
}

\section{Memory: 80 years of Social Work in Brazil - The III CBAS (Brazilian Congress of Social Workers), 1979's "Turning Congress"}

\author{
Maria Beatriz Costa Abramides \\ Doutora em Serviço Social, professora do Programa de \\ Pós-Graduação em Serviço Social da PUC-SP, \\ coordenadora do Núcleo de Estudos e Pesquisas em \\ Aprofundamento Marxista (Neam), São Paulo/SP, Brasil.
}

biabramides@gmail.com

Resumo: O artigo trata da contextualização histórica do Serviço Social no Brasil com destaque para o III CBAS, o conhecido "Congresso da Virada", realizado em 1979. Indica os elementos intrínsecos à conjuntura da luta de classes no país, contra a ditadura, anticapitalista na direção do socialismo, que se expande a partir de 1978. Apresentamos a inserção dos assistentes sociais no processo de lutas sociais, como trabalhadores que de forma coletiva rompem com o conservadorismo ao definirem a direção social da profissão voltada aos interesses imediatos e históricos da classe trabalhadora.

Palavras-chave: Serviço Social. Classe trabalhadora. Ruptura com o conservadorismo.

Abstract: The article is about the historical contextualization of Social Work in Brazil, and it highlights the III CBS (Congresso Brasileiro de Assistentes Sociais - Brazilian Congress of Social Workers), known as the "Turning Congress", which happened in 1979. It shows the intrinsic aspects of the country's class conflict situation - against dictatorship, anti-capitalist, towards socialism - which expanded from 1978. We present the social workers' integration into the class conflict process, as workers who collectively break with conservatism when they define the professional social direction, focused on the immediate and historical interests of the working class.

Keywords: Social Work. Working class. Break with conservatism.

\section{O Serviço Social — contextualização histórica}

O Serviço Social comemorou 80 anos de sua existência no Brasil em 2016, e sua primeira escola criada em 1936 situava-se à rua Sabará, em São Paulo. Fruto da disposição de jovens da ação católica, o curso foi iniciado para a formação de profissionais do sexo feminino pela referência teórica franco-belga seguida da vertente norte-americana na perspectiva da ação social. As pioneiras da Escola de Serviço Social no processo de urbanização e industrialização que avançara nos anos 1930 dirigiam sua ação às famílias operárias. Até esse período, a "questão social" era tratada como "caso de polícia" pelos sucessivos governos, à base de forte repressão aos operários organizados e em luta. A influência do anarcossindicalismo, entre os trabalhadores, fruto da experiência sindical dos imigrantes italianos, espanhóis e portugueses que ocuparam postos na indústria nascente, foi decisiva para a concepção e a prática sindical do 
movimento operário em sua formação. A seguir adentraram os socialistas e comunistas que, com os anarquistas, se tornaram referência de um sindicalismo classista, autônomo, de organização desde os locais de trabalhos, de ênfase na ação direta, mobilizações massivas e greves regidas pelo princípio da democracia operária. Porém o governo federal, no início do século, instituiu a Lei Adolfo Gordo, que proibia os estrangeiros de participar da luta sindical, iniciando-se a perseguição aos operários com prisões e exílio.

De outro lado, para que o crescimento econômico capitalista se expandisse pautado na gestão fordista-taylorista da força de trabalho, era necessário que o Estado implementasse programas sociais que atendessem às reivindicações dos trabalhadores e ao mesmo tempo liberasse a força de trabalho economicamente ativa dos gastos com serviços sociais, como educação e saúde, para que pudessem consumir. Portanto, o Estado, além de criar programas sociais, estabeleceu mecanismos de controle nas relações capital-trabalho, e entre outros instrumentos é criada a profissão de assistente social para atuar no âmbito da execução desses programas.

A partir de 1946, a Escola de Serviço Social se agrega à recém-criada Pontifícia Universidade Católica de São Paulo (PUC-SP), e em 1971 a ela se incorpora e se transfere para sua sede na Rua Monte Alegre, no bairro de Perdizes. Em 1972, o Curso de Serviço Social da PUC-SP inaugurou o primeiro mestrado em Serviço Social da América Latina, e em 1981 o primeiro doutorado do país.

Cursei Serviço Social na escola da Rua Sabará, de 1968 a 1971, e a militância e a consciência política iniciadas no movimento secundarista aí se aprofundaram com a atuação no Grêmio da Escola de Serviço Social (Gess), cuja organização se pautava nas reivindicações estudantis, em um período de repressão pela ditadura militar instaurada pelo golpe de 1964 . Nossa ação coletiva de resistência e de luta em 1968 foi muito intensa e nos formamos política e ideologicamente nas organizações de esquerda revolucionária. Ao entrar na universidade, filiei-me à Ação Popular (AP) marxista-leninista, cujos jovens vieram, em larga escala, da Juventude Estudantil Católica (JUC), alinhada à Teologia da Libertação, e depois se desvincularam para se inserir em uma ação revolucionária de superação do capitalismo e construção do socialismo. Os estudantes da AP eram majoritários no Serviço Social, o que nos levou a assumir a Executiva Nacional dos Estudantes de Serviço Social (Eness) na União Nacional dos Estudantes (UNE), à qual as executivas de curso se vinculavam. No Congresso da Eness em julho de 1968, em Fortaleza (CE), já debatíamos a necessidade de construir um projeto de formação profissional a partir da realidade brasileira. O XXX Congresso da UNE, em outubro de 1968, em Ibiúna, teve a participação de cerca de mil estudantes, 
sendo 152 mulheres, 25 delas dos cursos de Serviço Social. Em 1968, a polícia reprimiu o Congresso da UNE, fomos todos presos e enquadrados na Lei de Segurança Nacional, que até a anistia pesou muito sobre todas nós que permanecemos no país ou no exílio.

\section{Antecedentes do Congresso da Virada}

Na segunda metade dos anos 1970 presenciava-se uma efervescência da luta de classes no país no surgimento de um sindicalismo combativo contra a ditadura, o imperialimo, o capitalismo na perspectiva do socialismo, que se expressou na Articulação Nacional dos Movimentos Populares e Sindicais (Anampos), em 1978, e posteriormente na Central Única dos Trabalhadores (CUT), em 1983, com sua fundação. A partir do sindicalismo classista, a categoria dos assistentes sociais se organizou desde 1978, de norte a sul do país, nas entidades sindicais, retomando os sindicatos de assistentes sociais que ficaram fechados de 1969 até 1978 . Os profissionais que assumiram essas entidades vinham dos setores de esquerda que atuaram na clandestinidade, que estiveram à frente do processo de reconceituação da profissão, na articulação latino-americana de profissionais, nos movimentos populares que se iniciavam, como o feminista, de saúde, de moradia, do custo de vida, entre outros, e em experiências profissionais nos marcos de intenção de ruptura que eclodiam.

Nesse processo de organização sindical, os assistentes sociais se reconheceram como trabalhadores, em sua condição de assalariamento, e se organizaram participando ativamente de mobilizações, paralisações e greves, além de contribuírem na organização dos trabalhadores em serviço público, os quais até 1988 não podiam, por força de lei, se organizar em sindicatos. Do total de assistentes sociais, $62,8 \%$ se inseriram no serviço público nas diferentes esferas. Portanto, os sindicatos de assistentes sociais, assim como os dos médicos, enfermeiros, sociólogos, tiveram uma atuação junto aos trabalhadores em serviço público em processos de negociações e campanhas salariais, luta por cargos e salários, por serviços públicos de qualidade, movimento grevista na luta por reposição das perdas salariais etc. Em 1988, quando os trabalhadores puderam formar seus sindicatos, os assistentes sociais decidiram, por unanimidade, pela extinção dos sindicatos de categoria para a construção dos sindicatos por ramo de atividade econômica, seja por contratação, como o Sindicato dos Trabalhadores $\mathrm{Mu}$ nicipais, seja por atividade, como o Sindicato da Saúde e da Previdência nas esferas estadual e federal. Assim os sindicatos, a Associação Profissional dos Assistentes Sociais (Apas) e a Associação Nacional dos Assistentes Sociais (Anas) são extintos, com exceção de cinco sindicatos. Ora, 
se somos trabalhadores coletivos inscritos na divisão sociotécnica do trabalho, nossa organização deve se dar por ramo de atividade econômica e com os trabalhadores dos ramos devemos lutar por melhores condições de trabalho e salário.

Desde o primeiro momento os assistentes sociais, ao reorganizarem suas entidades sindicais e pré-sindicais - Apas, se filiaram a essa concepção e prática sindical classista, e são essas as determinações que incidirão forte e decisivamente na direção social da profissão dos anos 1980, que tem no III Congresso Brasileiro de Assistentes Sociais (CBAS), o conhecido "Congresso da Virada", sua expressão pública e coletiva da ruptura com o conservadorismo presente na profissão.

\section{0 "Congresso da Virada" - III CBAS — 1979}

O "Congresso da Virada", realizado de 23 a 27 de setembro de 1979, no Centro de Convenções do Anhembi, na cidade de São Paulo, irrompe marcado pela luta de classes ascendente no país. Em 1978, no I Encontro de Entidades Sindicais e Pré-Sindicais, éramos quatro entidades reorganizadas: Apassp São Paulo, Sindicato dos Assistentes Sociais de Minas Gerais, Apas Bahia e Apas Goiás. Esse encontro ocorreu em Belo Horizonte (MG), e deliberamos por: retomar a organização sindical dos assistentes sociais no país, realizar uma pesquisa nacional sobre salário, condições de trabalho e carga horária dos assistentes sociais para mobilizar os profissionais a partir de seus locais de trabalho para a luta sindical. $\mathrm{O}$ apoio político e financeiro do Centro Latino-Americano de Trabalho Social (Celats) fez com que no III Encontro de Entidades Sindicais e pré-sindicais em 1979, uma semana antecedendo o III CBAS, reuníssemos 29 entidades sindicais, pré-sindicais e de oposição sindical, na mesma concepção classista, articulada à Anampos, e a partir de 1983 à CUT classista e de lutas. Cabe registrar que nos anos 1990 a CUT consolidou e fortaleceu um giro sociodemocrata e se ateve às lutas institucionais, abdicando da ação direta. A partir de 2002, com os governos do PT de Lula e posteriormente de Dilma, manteve-se atrelada a um sindicalismo de cooptação, governista, muito distante do sindicalismo autônomo e classista de sua criação e em vigor nos anos 1980.

A participação ativa dos assistentes sociais organizados nas Apas e sindicatos estabeleceu uma ampla mobilização dos profissionais nas assembleias de base, na luta por cargos e carreiras no INSS, na luta por concurso público nas instituições estatais, na participação no I Congresso da Mulher paulista, na atuação e apoio às lutas feministas, na luta pelo Sistema Único de Saúde e reforma sanitária, na luta pela democratização das instituições com eleições para cargos de chefias, na participação em campanhas salariais 
unificadas dos trabalhadores em serviço público, na participação efetiva no movimento sindical classista, no apoio às greves em curso de trabalhadores, no apoio a projetos profissionais nos vários espaços sócio-ocupacionais voltados aos interesses dos usuários, na luta por direitos sociais, inserção na luta pela reforma agrária e urbana, apoio às ocupações de terras no campo e na cidade, na luta pelo ensino público, laico, universal, gratuito e de qualidade, na luta contra o pagamento da dívida externa, na solidariedade de classe às lutas latino-americanas e internacionais.

Essa ambiência de mobilização e lutas possibilitou que o III Encontro de entidades sindicais e pré-sindicais dos assistentes sociais sob a direção da Comissão Executiva Nacional de Entidades Sindicais e Pré-Sindicais (Ceneas), alguns dias antes do III CBAS, deliberasse pela continuidade da construção e da consolidação das entidades sindicais, coordenação das entidades pela Ceneas até a construção da Anas - entidade sindical nacional autônoma e independente do Estado, que ocorreu em 1983; continuidade na participação do movimento sindical classista e na fundação da CUT, realizada em 1983; continuidade de mobilização da categoria a partir de suas reivindicações específicas e as dos trabalhadores em serviço público; o reconhecimento dos assistentes sociais partícipes do trabalho coletivo, inseridos na divisão sociotécnica do trabalho; a atuação junto aos movimentos populares em defesa de suas reivindicações e apoio ativo e solidário às suas lutas, articulação com a Abepss, que iniciava o processo de renovação na formação profissional, que culmina com o currículo de 1982, referenciado na teoria social de Marx, na perspectiva da totalidade, e a rearticulação com o movimento estudantil. Iniciou-se ainda o debate relativo à necessidade de uma ação estratégica em todo o país para concorrer ao pleito do conjunto CFAS/ Cras, atualmente CFESS/Cress, que até 1979 encontrava-se sob a hegemonia dos setores conservadores e tecnocratas da profissão.

De outro lado, deliberamos por uma participação crítica e de contestação ao III CBAS, que até então era organizado pelo conjunto Cras/CFAS. Elaboramos um documento das entidades sindicais a ser divulgado, panfletado e trabalhado com a categoria durante o congresso e cuja nota apresentava os seguintes pontos: repúdio ao convite a representantes da ditadura militar para estar na mesa de abertura do congresso, críticas à limitada participação dos estudantes, ao preço alto das inscrições, à definição de temas e setorização dos debates, à ausência de participação da categoria em todo o processo. As dirigentes sindicais de assistentes sociais estiveram no CBAS, se organizaram pelas plenárias simultâneas por área de atuação e desde o primeiro momento sentiram a insatisfação dos congressistas. Chamaram a categoria para uma assembleia, a qual 
se transformou em assembleia diária, que interferiu e "virou" o congresso com as críticas necessárias. Isso culminou com a destituição da comissão de honra, sendo que no encerramento foram convidados representantes dos movimentos sociais combativos como referência de lutas. A plenária final deliberou pelo compromisso da profissão com a classe trabalhadora e os assistentes sociais se reconhecendo como trabalhadores em sua condição de assalariamento. A partir desse evento co- letivo, massivo, da categoria, designamos emblematicamente a erupção do projeto de ruptura com o conservadorismo por sua direção social nos anos 1980 e pelo Projeto Ético-Político profissional do Serviço Social brasileiro a partir dos anos 1990.

Recebido em 3/9/2016

Aprovado em 11/10/2016 